\title{
OS DETERMINANTES DO PROCESSO DE URBANIZAÇÃO DA REGIÃO NORDESTE DO BRASIL: 1970-1996
}

\author{
José Raimundo Vergolino ${ }^{1}$ \\ Marcelo Dantas $^{2}$
}

\section{INTRODUÇÃO}

O processo de urbanização apresenta um forte grau de associação com o desenvolvimento econômico de um país ou região; ou seja, há uma estreita correlação entre a parcela urbana da população e o grau de desenvolvimento da economia.

Nos países de baixa renda, a maior parte do esforço produtivo é empregado na agricultura. À medida que a economia se desenvolve, há uma modificação na sua estrutura setorial em detrimento do setor primário e em favor do secundário e do terciário. Em Mills e Hamilton (1989) existem dados que ilustram esse processo: em 1980, os países de baixa renda tinham em média $72 \%$ de sua força de trabalho empregada na agricultura; nos países de renda média, esse porcentual era de $43 \%$, enquanto nos países industrializados era de $7 \%$. A relação fundamental entre desenvolvimento e urbanização é inferida a partir da constatação de que as atividades do setor secundário e terciário são essencialmente urbanas; elas se beneficiam de inúmeras vantagens ao serem produzidas de forma concentrada no espaço. As transformações estruturais produzidas pelo desenvolvimento conduzem à "urbanização da economia" e, portanto, à urbanização da população.

No caso dos países do Terceiro Mundo, é observado um grande incremento das taxas de urbanização a partir da década de 1950. De acordo

${ }^{1}$ Professor da Faculdade Boa Viagem e aposentado do Departamento de Economia da UFPE/PIMES - PhD em Economia pela University of Illinois.

${ }^{2}$ Mestre em Economia pelo PIMES/UFPE e Técnico do IBGE. 
com Williamson (1989), as duas principais hipóteses desenvolvidas na literatura para os países em desenvolvimento consistem no fato de que o rápido crescimento das cidades e urbanização pode ser explicado por (1) altas taxas de crescimento da população que pressionam a estrutura de distribuição de terras, levando ao êxodo em direção às cidades; e (2) forças econômicas atraindo as pessoas para as cidades. São os fatores de expulsão da população do campo e atração para as cidades que, combinados, vão caracterizar o processo de urbanização no Terceiro Mundo.

A maior parte dos demógrafos é favorável à primeira hipótese, relacionada diretamente aos fatores de expulsão da população do campo. Uma combinação entre crescimento acentuado da população e falta de acesso à terra que expulsa parte da mão-de-obra do campo, gerando altas taxas de imigração nas cidades. Essa visão é essencial no modelo de excedente de mão-de-obra em Lewis (1954), assim como em Todaro (1969).

Como em outros países em desenvolvimento, a sociedade brasileira se torna eminentemente urbana por meio de um processo que apresenta grande intensidade e que ocorre em um período relativamente curto. Em 1940, a maior parte da população brasileira, $68,76 \%$, se encontrava em áreas rurais. Em poucas décadas, essa situação se inverte e o contingente urbano passa a ser sensivelmente maior: 78,36\% dos brasileiros vivia em cidades em 1996. É durante a década de 1960 que a população urbana nacional supera, pela primeira vez, a população rural.

O processo de urbanização brasileiro foi condicionado em grande parte pela concentração espacial das atividades econômicas, com o destaque para a atividade industrial, até o final da década de 1960. Por causa desse fenômeno, o processo de urbanização nacional não poderia se dar de forma homogênea entre as grandes regiões brasileiras. Tal processo, que atinge o Sudeste com maior intensidade na década de 1950, somente é observado nas demais regiões na década de 1970. O Sudeste mantém, até os dias de hoje, a primazia do sistema urbano do país.

O Nordeste, por outro lado, apresenta uma composição bastante distinta de suas populações rural e urbana. Em 1991, respondia por 46,4\% da população rural brasileira e por apenas $23 \%$ da urbana; ou seja, a participação da população rural nordestina era, na época, duas vezes maior que a sua participação na população urbana nacional (MARTINE, 1994).

A análise da formação da economia nordestina representa uma das formas de entender não só a estrutura do atual sistema urbano nordestino, em grande parte concentrada na faixa litorânea, como também o seu povoamento, caracterizado pela grande concentração da população nas áreas rurais. A articulação com o mercado nacional, a partir de 1930, e o processo 
de industrialização incentivada, a partir da década de 1960, são elementos que, combinados com a alta densidade populacional nos quadros rurais da Região, levam a que a migração rural-urbana constitua um dos principais componentes demográficos (juntamente com o crescimento vegetativo) do incremento da população urbana regional, a partir da década de 1950.

O estudo dos principais determinantes do processo de urbanização da Região está diretamente ligado à combinação dos fatores de expulsão da população dos quadros rurais com os fatores de atração dos contingentes em direção às cidades. Esse é o ponto central da estrutura do presente trabalho, cujo objetivo central é investigar o processo de urbanização da Região Nordeste. A seção 1 busca mostrar, a partir da análise de literatura de história econômica, a importância da formação econômica da Região na definição de seu sistema urbano. Em seguida, destacam-se alguns aspectos da migração rural-urbana e sua importância no crescimento da população urbana nordestina. A seção 2 aborda a dinâmica recente do processo de urbanização regional e sua relação com a concentração das atividades econômicas verificada no período estudado.

A análise do modelo teórico, do modelo de estimação e da metodologia de estimação constituem o objeto da seção 3. Os resultados das estimações encontram-se na seção 4.

\section{REGIÃO NORDESTE: FORMAÇÃO ECONÔMICA E URBANIZAÇÃO}

A formação da economia nordestina está diretamente ligada à atividade econômica que veio a justificar a ocupação brasileira no início de sua colonização por Portugal: o açúcar. Observada em uma perspectiva ampla, a colonização do século XVI surgiu fundamentalmente ligada à atividade açucareira (FURTADO, 1998; PRADO, 1978; HOLANDA, 1975). O empreendimento açucareiro progride de forma admirável até meados do século XVII, quando se modifica a estrutura do mercado externo em face da concorrência com o açúcar produzido nas Antilhas. Os dois grandes núcleos iniciais da produção se encontravam em Pernambuco e na Bahia (a produção de São Vicente era considerada de segundo plano).

$\mathrm{O}$ acesso por outros produtores coloniais ao mercado da economia açucareira era pequeno; entretanto, havia um artigo de consumo de importância que podia ser suprido internamente com grandes vantagens: a carne. A demanda por carne e animais para tração combinada com a abun- 
dância de terras leva à criação, dentro do próprio Nordeste, de um segundo sistema econômico, dependente da economia açucareira. A facilidade com que as fazendas de gado se alastram pelo sertão nordestino se explica pela grande disponibilidade de terras e pela reduzida necessidade de capital físico. Os rebanhos penetram costa adentro, cruzando o São Francisco e o Tocantins e, em fins do século XVII, ocupam o interior do atual Estado do Piauí (PRADO, 1978, p. 68).

As formas que assumem os dois sistemas da economia nordestina - o açucareiro e o criatório - revelam-se elementos fundamentais no entendimento do que vem a ser a atual economia nordestina e conseqüentemente na forma como se deu a ocupação do espaço na região. A queda no preço do açúcar no mercado externo, a partir de meados do século XVII, leva a economia nordestina a um longo período de atrofiamento, com redução de sua renda per capita, até o começo do século XIX, quando se verifica nova recuperação dos preços (FURTADO, 1998).

O processo de formação da economia nordestina e, conseqüentemente, de seu povoamento, é fundamental no entendimento da organização espacial do sistema urbano regional. A concentração das maiores e mais importantes cidades no litoral é o resultado natural da importância das exportações de determinados produtos primários diretamente ao mercado externo, num período em que o mercado nacional não estava articulado. A rede urbana surgiu como decorrência desse mercado externo e foi se definindo com a formação das primeiras vilas-portos. Cidades portuárias como Recife e Salvador ganham importância porque funcionam como base para o escoamento de produtos primários para o exterior, o que lhes permitirá, inclusive, possibilidade de apresentar, já no final do século XIX, algum surto de atividade industrial.

A evolução da formação dos principais centros dinâmicos da Região Nordeste revela-se fundamental no entendimento desse processo de concentração da população predominantemente no litoral do seu território.

A importância de Recife, bem como a de Salvador, em termos de hegemonia econômica e política na Região apresenta-se contundente. $\mathrm{Na}$ cidade do Recife é criado o núcleo da logística de comercialização do principal produto de exportação no período colonial que, mesmo com a decadência da atividade açucareira, ainda permite que Pernambuco mantenha o seu domínio econômico no Nordeste "durante todo o período de 1889-1937, embora a saúde econômica da Região declinasse vertiginosamente em relação ao progresso registrado no Centro Sul" (LEVINE, 1975, p. 151). Como mostra Tollenare (1817), a cidade do Recife também se torna um grande centro de comercialização do algodão produzido no Sertão do Nordeste durante o século XIX. 
As usinas marcam o início da revolução industrial do açúcar no Nordeste brasileiro em fins do séc. XIX. ${ }^{3}$ Nesse mesmo período, é observado um surto de industrialização no Recife, capitaneado pela indústria de fiação e tecelagem. Na época, podiam ser encontradas fábricas de alimentos, bebidas, roupas, vassouras, charutos, etc. O aparecimento das usinas vem inclusive facilitar a indústria incipiente, tendo em vista que liberava, ou expulsava, do campo levas de trabalhadores que iam constituir, no Recife, mão-deobra barata; criava mercado para certos produtos como sacaria, máquinas, etc.; e estabelecia mudanças nas relações de produção na zona rural com a expansão da economia de mercado em detrimento da economia de subsistência.

A entrada de fluxo expressivo de pessoas transforma-se em um problema de dimensão econômica e, especialmente, social, quando se considera que a economia do Recife não se expandiu a ponto de absorver esse excedente de mão-de-obra. Em 1950, o peso das atividades urbanas não tinha se alterado significativamente no caso de Recife, nem em relação a Salvador. As duas cidades tinham 9,2\% e 6,7\%, respectivamente, do total de suas populações trabalhando em atividades urbanas.

A formação das mais importantes cidades da Região é reveladora do processo de concentração da população e das atividades econômicas nordestinas. Recife, Salvador e Fortaleza vão originar as três RMs do Nordeste, que irão concentrar não só a maior parte da população, mas também as principais atividades econômicas. A análise histórica permite que se observe a estrutura sobre a qual se assentou o sistema urbano nordestino a partir de meados do século XX, quando a população passa a se urbanizar a taxas expressivas a partir do deslocamento dos quadros rurais pata os centros urbanos. Tal fenômeno será analisado nas seções seguintes, com ênfase nos processos migratórios e na intensidade com que a população passa a viver nas áreas urbanas.

\section{Principais aspectos da migração}

Assim como no caso dos países em desenvolvimento, a migração assume importância fundamental na formação da rede urbana do Nordeste. O trabalho de Duarte (1979) revela-se esclarecedor quanto ao entendimento dos principais aspectos desse fenômeno na Região. ${ }^{4}$

${ }^{3}$ Singer (1977, p. 299).

${ }^{4}$ Duarte utiliza como amostra o caso de três cidades do estado de Pernambuco: Recife, Caruaru e Petrolina. Foram entrevistadas 658 pessoas nas três cidades, das quais $54,9 \%$ eram migrantes. Esse número está de acordo com o elevado porcentual de migrantes nas áreas urbanas verificado nos países em desenvolvimento. 
Um ponto fundamental no processo migratório se encontra nas razões que levam os contingentes a migrar de áreas rurais para áreas urbanas, ou de pequenas áreas urbanas em direção às cidades maiores. O trabalho de Duarte mostra que, dentre os motivos pelos quais os migrantes deixam seu primeiro lugar de residência, há clara predominância dos "fatores de expulsão"; embora também possam ser identificados alguns "fatores de atração" exercendo influência considerável. As alegações mais utilizadas para emigração são o desemprego e a insatisfação com o salário atual. No primeiro caso, tem-se a presença clara de uma força que expulsa o migrante de sua área de origem; no segundo, há uma combinação de fatores de expulsão e atração, já que se supõe a avaliação da diferença nos ganhos entre os lugares de origem e destino.

Os fatores responsáveis pela expulsão da população dos quadros rurais, associados ao avanço da industrialização do país e também da própria Região, dão a tônica do intenso movimento de emigração dos quadros rurais nordestinos. A dinâmica demográfica reflete não somente os principais aspectos estruturais dos vários componentes (industrialização, urbanização, desruralização, etc.) responsáveis pela formação da economia e da sociedade no Brasil, mas também as relações que se estabelecem entre o centro dinâmico da economia do País e uma de suas regiões periféricas.

$\mathrm{O}$ crescimento da população urbana da Região tem seus principais componentes no crescimento vegetativo e na migração com destino às áreas urbanas. Martine (1989) estima a taxa de crescimento da população urbana em 4,4\% e 4,1\% para o Nordeste nas décadas de 1960 e 1970, respectivamente. $\mathrm{O}$ crescimento vegetativo responde por $3 \%$ do total e a migração por $1,4 \%$, na década de 1960 . Esses valores são $2,5 \%$ e $1,6 \%$ para a década de 1970, respectivamente. Apesar do maior peso do crescimento vegetativo, é a migração em direção às cidades que vai permitir o grande diferencial de crescimento entre áreas urbanas e rurais, o que faz com que a população urbana supere, numericamente, a rural, na década de 1970.

Embora grande parte da emigração rural tenha se orientado para fora da Região, uma substancial parte desse contingente se estabeleceu em cidades do próprio Nordeste. Em Moura (1975), encontra-se o quadro da dinâmica migratória das três RMs do Nordeste para a década de 1960. Estima-se que, do começo até meados da década de 1960, cerca de 435 mil pessoas passaram a residir no conjunto dos municípios de Salvador, Recife e Fortaleza. A maior parte desses migrantes não teria procedido diretamente dos quadros rurais (apenas $14 \%$ dos imigrantes do Recife teriam partido diretamente de áreas rurais; $22 \%$ e 36\% para Salvador e Fortaleza, respectivamente). 
A tendência de transferência de contingentes significativos em direção às cidades se acentuou na década seguinte, 1970/80. Pela primeira vez, em escala nacional, ocorreu decréscimo absoluto da população residente nos quadros rurais. Mesmo no Nordeste, onde este processo ocorria com menor intensidade que no caso do Centro-Sul, o crescimento da população no campo foi de apenas $0,5 \%$ a.a., contra $4,1 \%$ da população urbana. $O$ significado dessas taxas é a continuidade de um processo de relocalização de contingentes significativos da população do campo para a cidade. No Nordeste, pela primeira vez, a população residente nas áreas urbanas superou a residente no campo: 50,5\% e 49,5\% respectivamente, em 1980.

Para Moura (1985), "a população residente nos quadros rurais de vários estados brasileiros já não mais apenas transborda para as cidades, mas é ela própria que, em grande parte, se transporta para estas" (MOURA, 1985, p. 160). Nessa década, a Região continua apresentando substanciais transferências de população do campo para as cidades. Estima-se que, em termos absolutos, pelo menos 4,5 milhões de pessoas tenham deixado os quadros rurais da Região durante a década de 1980, dos quais 2,3 milhões teriam emigrado para o resto do País e o restante se deslocado para as áreas urbanas da própria região.

O componente migratório é a principal explicação para o diferencial entre os ritmos de crescimento observados nas populações das áreas rurais e urbanas, além do próprio decréscimo, em termos absolutos, verificado na população rural nordestina.

\section{DINÂMICA DA URBANIZAÇÃO}

A dinâmica da urbanização na Região durante o século XX está fortemente ligada à formação de sua economia e sua integração com o mercado nacional, a partir da década de 1930. A emergência de um padrão de acumulação urbano-industrial comandado pelo Centro-Sul leva a que o Nordeste se integre na nova divisão inter-regional do trabalho, sobretudo, como consumidor de produtos manufaturados do pólo hegemônico da economia (CANO, 1985). A dinâmica dessa integração, aliada à tentativa de industrialização incentivada, a partir da década de 1960, vai dar a tônica do processo de urbanização da Região no pós-guerra.

O processo de formação da rede urbana nordestina, baseado primordialmente em cidades cuja principal função era a de escoamento de mercadorias ao exterior, condicionou uma ocupação regional caracterizada pela grande concentração da população nas áreas rurais. $\mathrm{O}$ avanço de forças 
produtivas essencialmente urbanas (indústria e comércio) resultou no rápido desenvolvimento do sistema urbano baseado na sua formação original, a partir de meados do século XX. O processo migratório das áreas rurais para as urbanas adquire grande importância no crescimento da população urbana. O Nordeste não foge à regra do que é observado na maior parte dos países de Terceiro Mundo após a II Guerra: um intenso fluxo migratório em direção às cidades.

A evolução da população rural e da urbana permite uma visão clara do dinamismo do processo de urbanização da Região nas últimas décadas. As estatísticas mostram que, em pouco mais que do que 50 anos, a sociedade deixa de ser eminentemente rural para se tornar uma sociedade urbana. Em 1940, cerca de 23,42\% da população se encontrava em áreas urbanas, enquanto em 1996 esse porcentual sobe para 65\%.

Em Pernambuco, por exemplo, a população urbana ultrapassa a rural na década de 1960. Esse Estado se destaca por apresentar um grau de urbanização sempre maior que a média regional; em 1996, já possui $74 \%$ da população em áreas urbanas, contra $65 \%$ da Região. Uma das explicações para o grau de urbanização pernambucano ser sempre maior que a média nordestina tem origem histórica. O Maranhão, por outro lado, se afasta sensivelmente dessa média, apresentando $52 \%$ da população nas áreas urbanas. Esse Estado se destaca pelo grande contingente de sua população rural, o maior, em termos relativos, dentro da Região. A Bahia, apesar de apresentar o sistema urbano com o maior número de cidades, e de possuir uma das três RMs, só vem apresentar superioridade numérica da população urbana em relação à rural na década de 1980. O Ceará também se destaca como um dos estados mais populosos e revela, a partir de 1970, grau de urbanização acima da média da Região.

Pode-se também analisar a transformação da estrutura urbana da Região a partir da evolução da distribuição das cidades por classe de tamanho de sua população. A evolução do sistema de cidades no intervalo considerado (1970/96) guarda proporções consideráveis: o número de cidades com mais de 20 mil habitantes na Região é mais que quintuplicado, passando de 36, em 1970, para 201 cidades, em 1996. A década de 1970 confirma, na Região, o dinamismo observado em todo o País: o número de cidades passa de 36, em 1970, para 118, em 1980. Esse crescimento regional no número de cidades com mais de 20 mil habitantes deve-se, principalmente, aos estados de Pernambuco, Bahia e Ceará, os mais populosos em todo o período: foram responsáveis por $72 \%$ do aumento no número de cidades na década de 1970 . Nessa década, a classe de cidades com população entre 20 e 50 mil habitan- 
tes foi responsável por cerca de $67 \%$ no incremento no número de cidades com mais de 20 mil habitantes, passando de 21 para 76 cidades em 1980.

Os números de 1991, referentes à década de 1980, mostram um aumento menor que o observado na década anterior: o número de cidades com mais de 20 mil habitantes aumenta em 61 cidades contra um aumento de 82 cidades na década de 1970. Mais uma vez, a classe de cidades com população entre 20 e 50 mil habitantes é responsável pela maior parte da elevação no número de cidades: cerca de $70 \%$ do aumento. Finalmente, em relação à década de 1990, a Contagem Populacional de 1996 revela o acréscimo de 22 cidades no grupo de cidades com mais de 20 mil habitantes no intervalo 1991/96.

A tendência à grande concentração da população nos grandes centros administrativos é detectada em praticamente todos os Estados do Nordeste. Questões de concentração do crescimento econômico, mencionadas anteriormente, associadas a questões históricas e políticas, estão por trás desse fenômeno. Capitais como Recife, Salvador e São Luís foram, desde a colonização, cidades portuárias responsáveis pelo escoamento da produção ao exterior. O dinamismo de suas atividades levou a que, historicamente, a maior parte da população se concentrasse no litoral - situação que não se alterou significativamente até os dias de hoje. De acordo com Lubambo (1995), em 1991 cerca de 59\% da população nordestina vivia em $21 \%$ de seu território, correspondentes ao seu eixo litorâneo. As capitais administrativas possuem ainda grande capacidade política de atração de investimentos públicos em infra-estrutura, educação e saúde, o que lhes confere um grande diferencial no momento da decisão locacional da população.

A evolução da população dos municípios das capitais permite que se verifique o fenômeno. A Tabela 1 mostra esta evolução, assim como a taxa de crescimento, no intervalo 1970/96.

A década de 1970 apresenta um grande dinamismo no crescimento da população das capitais. A tendência de aumento da concentração nas maiores cidades está de acordo com o que foi observado em todo o País e encontra suas raízes na concentração das atividades econômicas, particularmente a industrialização, verificada também no Nordeste. Enquanto a população da Região cresce a uma taxa de $2,16 \%$ ao ano, a maior parte das capitais cresce a taxas que variam entre $4,08 \%$ e $5,41 \%$.

Há, entretanto, uma exceção que se destaca: Recife cresce a uma taxa sensivelmente inferior, da ordem de 1,24\%. Recife também apresenta taxas de crescimento inferiores às demais capitais na década de 1980 e no intervalo 1991/96. Uma das explicações para o caso do Recife é a emigração líquida negativa do município centro da RM em direção aos periféricos. 
Dentre as três RMs da Região, a de Recife apresentou, nas décadas de 1970 e 1980, uma maior importância nos deslocamentos intrametropolitanos.

Tabela 1 - NORDESTE - POPULAÇÃO RESIDENTE E TAXA DE CRESCIMENTO, SEGUNDO OS MUNICÍPIOS DAS CAPITAIS 1970/1996

\begin{tabular}{|c|c|c|c|c|c|c|c|}
\hline \multirow{2}{*}{ Capitais } & \multicolumn{4}{|c|}{ População Residente } & \multicolumn{3}{|c|}{ Taxa de Crescimento (\%) } \\
\hline & 1970 & 1980 & 1991 & 1996 & $1970 / 80$ & $1980 / 91$ & $1991 / 96$ \\
\hline São Luís & 265.486 & 449.432 & 696.371 & 780.833 & 5,41 & 4,06 & 2,36 \\
\hline Teresina & 220.487 & 377.774 & 599.272 & 655.473 & 5,53 & 4,28 & 1,84 \\
\hline Fortaleza & 857.980 & 1.307 .611 & 1.768 .637 & 1.965 .513 & 4,30 & 2,78 & 2,17 \\
\hline Natal & 264.379 & 416.898 & 606.887 & 656.037 & 4,66 & 3,47 & 1,60 \\
\hline João Pessoa & 221.546 & 329.942 & 497.800 & 549.363 & 4,06 & 3,81 & 2,03 \\
\hline Recife & 1.060 .701 & 1.200 .378 & 1.298 .229 & 1.346 .045 & 1,24 & 0,71 & 0,74 \\
\hline Maceió & 263.670 & 399.098 & 629.041 & 723.230 & 4,24 & 4,22 & 2,88 \\
\hline Aracaju & 183.670 & 293.131 & 402.341 & 428.194 & 4,79 & 2,92 & 1,27 \\
\hline Salvador & 1.007 .195 & 1.501 .981 & 2.075 .273 & 2.211 .539 & 4,08 & 2,98 & 1,30 \\
\hline
\end{tabular}

FONTE: IBGE, Censos Demográficos de 1970 a 1991 e Contagem da População de 1996.

Na década de 1980, todas as capitais apresentaram taxa de crescimento inferior à observada na década anterior. Esse comportamento populacional das maiores cidades nordestinas está de acordo com a tendência de arrefecimento da concentração nas maiores cidades verificada em todo o território nacional, e suas principais causas foram abordadas na seção anterior. Apesar da queda no ritmo de crescimento, são taxas que, à exceção de Recife, estão sensivelmente acima do crescimento populacional da Região, que foi de $1,83 \%$ ao ano.

Apesar desse arrefecimento, as capitais nordestinas apresentaram, na média, crescimento mais expressivo que as capitais dos estados do Sul e Sudeste. Martine (1994) sugere que, além de um crescimento demográfico mais acelerado no Nordeste, esse fato reflete, em parte, um fenômeno estatístico, pois quanto menor o nível relativo de urbanização, mais fácil o crescimento da população urbana que, na Região, se concentra especialmente nas capitais estaduais e RMs. Além disso, há de se considerar a redução do saldo migratório líquido da emigração regional, observado na década de 1980. A queda nas taxas de crescimento da população também é observada no intervalo 1991/96, com todas as capitais apresentando taxas inferiores às da década de 1980 .

O padrão de crescimento das capitais se repete quando se trata das RMs de Fortaleza e Salvador. O seu crescimento é de 4,3\% e 4,41\% ao ano, respectivamente, na década de 1970 (Tabela 4). Na década de 1980, há uma queda nestas taxas (3,49\% e 3,18\%) e, no intervalo 1991/96, a RM de Fortaleza ainda apresenta taxa relevante de $2,32 \%$. 
O fenômeno da metropolização se caracteriza pela grande importância demográfica e econômica de uma cidade sob um conjunto de cidades de uma região ou país. A população das três RMs, bem como sua proporção em relação à população urbana, para o intervalo 1980/96, podem ser observadas na Tabela 2.

Tabela 2 - NORDESTE - POPULAÇÃO RESIDENTE SEGUNDO AS RMS, 1980/1996

\begin{tabular}{l|c|c|c|c|c|c}
\hline Regiões & \multicolumn{3}{|c|}{ População Residente } & \multicolumn{3}{c}{ Proporção da Pop. Urbana } \\
\hline Metropolitanas & 1980 & 1991 & 1996 & 1980 & 1991 & 1996 \\
\hline RM de Salvador & 1.752 .157 & 2.496 .521 & 2.709 .084 & 36,93 & 35,62 & 34,61 \\
RM de Recife & 2.273 .761 & 2.919 .979 & 3.087 .967 & 58,84 & 57,86 & 56,38 \\
RM de Fortaleza & 1.542 .173 & 2.307 .017 & 2.582 .820 & 53,59 & 55,48 & 54,79 \\
\hline
\end{tabular}

FONTE: IBGE, Censos Demográficos de 1980 a 1991 e Contagem da População de 1996.

O peso de cada RM dentro do sistema urbano de seu estado é bastante expressivo. Em 1980, as RMs de Recife e Fortaleza respondiam por mais de $50 \%$ da população urbana de seus estados. No caso da RM de Recife, esse valor se aproximava de 60\%. É esta RM que apresenta, dentro do intervalo, o maior grau de primazia urbana, apesar de apresentar a menor taxa de crescimento de sua população. A RM de Salvador revela proporções menores que as demais; entretanto, são valores que exprimem a grande importância desta RM para o sistema de cidades da Bahia, além da própria Região. Cerca de $37 \%$ da população urbana da Bahia se encontra em sua RM, em 1980, com este valor apresentando uma leve tendência de queda e chegando a 34,61\% em 1996.

$\mathrm{O}$ peso do conjunto da população das três RMs, em relação à Região, também expressa a importância do fenômeno da metropolização. Em 1980, 31\% da população urbana do Nordeste se encontrava em uma de suas RMs. Esse porcentual é de cerca de 30\% e 28,9\%, em 1991 e 1996, respectivamente. Esses números refletem a estratégia de desenvolvimento implementada na Região. A maior parte dos investimentos na indústria incentivada se dirigiu às três RMs, no intuito de utilizar as economias de escala que suas estruturas urbanas ofereciam.

Maia Gomes e Vergolino (1995) estimaram os produtos internos brutos de diferentes sub-regiões do Nordeste no intervalo 1970/92. Dentre elas, encontra-se a sub-região compreendida pelas três regiões metropolitanas nordestinas. A evolução do seu produto deixa clara a importância da industrialização incentivada em relação à concentração da atividade econômica. Em 1980, cerca de 36\% do PIB da Região se concentrava no conjunto de suas RMs. Esse porcentual é de 51,43\%, em 1992, ou seja, mais da metade 
da produção global da Região ocorria em suas RMs - um fenômeno bastante significativo de concentração espacial do produto bruto regional.

Santos (1997) analisa o perfil industrial das RMs nordestinas; o autor mostra que os grandes complexos industriais da Região estão nela localizados. A fase de industrialização incentivada em Salvador teve na consolidação da indústria petroquímica seu principal representante. O Complexo Petroquímico de Camaçari passa a funcionar a partir de 1978 e representa o principal complexo industrial nordestino. De acordo com o pesquisador, a dinâmica da indústria química e petroquímica refletiu em uma elevação considerável da participação do setor industrial no total do PIB estadual de $12 \%$, em 1960, para 30\%, em 1990.

Para Maia Gomes e Vergolino (1995), a concentração das atividades econômicas foi conseqüência do processo de industrialização, a partir de 1960, a partir do mecanismo de incentivos fiscais e creditícios criados pelo governo federal. $\mathrm{O}$ desenvolvimento da atividade manufatureira levou ao crescimento das atividades de serviços públicos e privados. Em relação aos serviços públicos, destacam-se os volumosos investimentos em saneamento, comunicações e energia elétrica. O efeito multiplicador do emprego e da renda criado por esses serviços sobre a estrutura das RMs revelou-se de elevadas proporções. $\mathrm{O}$ grau de concentração das atividades econômicas foi tal que "...podemos dizer que o crescimento econômico nordestino concentrou-se, fundamentalmente, nas três regiões metropolitanas, enquanto toda a Zona da Mata e, sobretudo, o Semi-Árido se retardavam cada vez mais" (MAIA GOMES e VERGOLINO, 1995, p. 83)

O resultado geral da coexistência de áreas urbanas com produção industrial de alta produtividade e áreas rurais deprimidas - cuja base da produção agrícola é de subsistência e que, além disso, encontram-se sujeitas a crises periódicas de produção em decorrência das secas - pode se constituir em um fator explicativo da migração de contingentes em direção às cidades.

A urbanização no Nordeste acompanha a tendência nacional. Em algumas décadas, a população se torna eminentemente urbana. É um processo concentrado no tempo e que forma um sistema urbano caracterizado pela primazia das RMs e pelo grande peso das demais capitais estaduais. A população não apenas se torna urbana, como passa a residir, em grande parte, em cidades com mais de 20 mil habitantes - o que significa que a concentração urbana vem se intensificando desde a década de 1960, apesar da redução desse ritmo observada a partir da década de 1980. 


\section{MODELO TEÓRICO}

Nas últimas décadas, vários teóricos em economia urbana vêm construindo modelos com considerável poder de explicação dos principais aspectos da estrutura espacial urbana, tais como a grande variação na intensidade do uso do solo nas áreas urbanas (p. ex.: as construções são maiores nos centros da maior parte das cidades, enquanto diminuem de tamanho à medida que se dirige aos subúrbios).

O modelo construído por Mills e Muth (ver BRUECKNER, 1987 e MILLS e HAMILTON, 1989) é seminal para a análise da estrutura urbana. É construído em torno da observação de que as diferenças entre os custos com o deslocamento dentro de uma área urbana são contrabalançadas por diferenças nos preços da área de moradia. Sua principal preocupação é com o setor residencial, considerado o mais importante. Será apresentada, a partir de então, uma versão simplificada desse modelo.

Admite-se no modelo que a área urbana possui um centro prédeterminado. A cada ponto a partir do centro, $\phi$ radianos de um círculo estão disponíveis para uso urbano. Na medida em que um círculo tem área igual a $2 \pi$, $\phi$ não pode exceder $2 \pi$. O resto da área, $2 \pi$ - $\phi$ radianos, não está disponível para uso urbano (talvez por condições topográficas). Admite-se também que toda a área onde os trabalhadores vão trabalhar se encontra em semicírculo com raio de $u$ milhas, que é denominado CBD ("central business district"). A área do CBD é de $(\phi / 2) u^{2}$ e um total de $N$ pessoas trabalham lá (os termos $\phi, u$ e $N$ são exógenos em relação ao modelo). A área disponível além do CBD é usada para residência dos $N$ trabalhadores, e o total de terra disponível para moradia a $u$ milhas do centro é dado por $(\phi / 2) u^{2}-(\phi / 2) u^{2}$.

Cada trabalhador se desloca de seu local de residência até o centro da cidade e, para tanto, incorre num custo de deslocamento que depende unicamente de uma distância tomada em linha reta entre aqueles dois pontos. Segue daí que o aluguel de uma determinada área, assim como a intensidade de seu uso, dependem dessa distância em linha reta. Dessa forma, toda a área distante $u$ milhas do centro tem o mesmo valor de aluguel e mesma intensidade de uso da razão capital/terra. Os valores dos insumos capital e terra a uma distância de $u$ milhas do centro são designados por $K(u)$ e $L(u)$, respectivamente; ou seja, os serviços de moradia são produzidos utilizandose esses dois insumos.

A função de produção é considerada na forma Cobb-Douglas e o produto de serviços de moradia a cada $u$ é definido como $X_{S}(u)$ e depende dos insumos capital e terra da seguinte forma: 


$$
X_{S}(u)=A L(u)^{\alpha} K(u)^{I-\alpha}
$$

onde $\alpha$ é o parâmetro de distribuição que mostra a taxa de retorno de cada insumo em relação à renda do aluguel.

Convenciona-se, ainda, que todos os trabalhadores recebem o mesmo salário $w$ (exógeno ao modelo) e possuem as mesmas preferências. A função de demanda por moradia de cada trabalhador vivendo a $u$ milhas, $x_{D}(u)$, é definida como

$$
x_{D}(u)=B w^{\theta l} p(u)^{l-\theta 2}
$$

onde $B$ é o parâmetro de escala; $\theta_{1}$ e $\theta_{2}$ são as elasticidades renda e preço da demanda por moradia; $p(u)$ é a taxa de aluguel por "serviços de moradia".

Moradia não é um bem inferior, de maneira que $\theta_{1}>0$ e $\theta_{2}<0$ (estudos recentes ${ }^{5}$ sugerem que $\theta_{1}=1$ e $\theta_{2}=-1$ ). A demanda total, $X_{D}(u)$, é igual à demanda por trabalhador multiplicada por $N(u)$, ou seja,

$$
X_{D}(u)=x_{D}(u) N(u)
$$

Tem-se então que, em equilíbrio, a demanda e a oferta devem-se igualar a cada $u$ milhas, de maneira que

$$
X_{D}(u)=X_{S}(u)
$$

Como foi adotado anteriormente, $\phi$ é a medida em radianos da área disponível para moradia a cada $u$ milhas, de maneira que $L(u)=\phi u$ é a extensão do semicírculo disponível para moradia a $u$ milhas do centro. Essa área deve alojar todos os $N$ trabalhadores na área urbana. Dessa forma, se $N(u)$ trabalhadores vivem a $u$ milhas do centro, o número total de trabalhadores da área urbana é dado pela integral de $N(u)$ para valores que vão de $u$ a $\underline{u}$, onde $\underline{u}$ é o limite da área urbana, definida por $N(u) d u=N$.

O modelo permite que se obtenha o valor de cada variável a cada $u$ milhas entre $u$ e $\underline{u}$. Uma vez resolvido, obtém-se um quadro completo do setor residencial da área urbana. Pode-se, por exemplo, a partir da solução de $N(u)$, ser computada a densidade da população a cada $u$ milhas de área disponível para uso urbano.

Uma vez estabelecidas as condições básicas de equilíbrio urbano, o próximo passo é considerar o equilíbrio do modelo para o caso de uma cidade aberta à migração ("open-city case"). Quando o fluxo de pessoas é permitido, a utilidade não é apenas definida internamente, dependendo também de condições externas à cidade. Esse foi o tratamento dado por Brueckner (1990), que considerou a construção de um modelo teórico de urbanização

${ }^{5}$ Mills e Hamilton (1989). 
para os países em desenvolvimento baseado nos fluxos migratórios em direção à cidade. Utilizou para tanto o modelo padrão desenvolvido por Mills e Muth.

Brueckner afirma que o crescimento urbano origina-se de duas fontes: a migração rural urbana e o aumento natural da população na cidade. A migração rural-urbana desempenha um papel muito importante. De acordo com o estudioso, "a lição mais importante dos trabalhos empíricos nesta área é que a migração nos países do terceiro mundo é economicamente racional, com os migrantes atraídos à cidade pela perspectiva de um melhor padrão de vida" (BRUECKNER, 1990, p. 588). O autor afirma ainda que "na medida em que o estímulo à migração rural-urbana é dado pelo ganho esperado na cidade, uma alta taxa de desemprego urbano não reduziria tal migração se os salários no setor urbano moderno forem consideravelmente maiores que os salários na agricultura" (BRUECKNER, 1990, p. 589)

A determinação da população de equilíbrio da cidade é atingida quando se têm os mesmos ganhos, a mesma utilidade, na cidade e no campo. A equação que expressa a relação fundamental no modelo é definida por

$$
y_{a}=y-t x\left(P, y, t, r_{d}\right)
$$

onde $y_{a}$ é a renda no campo, $y$ é a renda na cidade, $t$ é o custo por quilômetro para que o trabalhador chegue ao local de trabalho (que fica no centro da cidade), $x$ é a distância do centro até os limites da cidade, $P$ é a população total da área urbana e $r_{a}$ é o aluguel da terra no campo.

A equação 5 define implicitamente o tamanho da população urbana $P$, que iguala os ganhos reais da área urbana e do campo para os valores dados de $y_{a}, y, t$ e $r_{a}$, permitindo $P=P\left(y_{a}, y, t, r_{d}\right)$. Brueckner mostra que $P$ é função crescente da renda na área urbana $y$, e do aluguel da terra no campo e função decrescente da renda no campo $y_{a}$ e do custo com transportes $t$.

A fim de facilitar a implementação empírica do modelo, é feita a suposição de que a função utilidade utilizada no modelo é uma função CobbDouglas. Brueckner demonstra que, sob esta suposição, $x\left(P, y, t, r_{d}\right) \equiv x$ $\left(P, 1, t / y, r_{a} / y\right)$. Substituindo em 5, tem-se $y_{a}=y-t x\left(P, 1, t / y, r_{a} / y\right)$, e dividindo por $y$ encontra-se:

$$
Y=1-T x(P, 1, T, R)
$$

Onde

$$
\text { (7) } Y=y_{a} / y
$$

(8) $T=t / y$

(9) $R=r_{a} / y$

A equação (6) mostra que, no caso Cobb-Douglas de equilíbrio, a população depende apenas das razões $Y, T$ e $R$, e não do nível das outras variáveis do modelo. A diferenciação de (6) permite mostrar que um aumento 
nas razões $y_{a} / y$ ou $t / y$ leva a uma queda em $P$, enquanto um aumento em $r_{a}$ / y leva a uma variação positiva naquela variável.

Pode-se também analisar a evolução da população residente em áreas urbanas a partir da relação entre urbanização e renda per capita. Esse tem sido um tópico de grande interesse por parte de pesquisadores que estudam níveis de urbanização internacional. Mills e Becker (1986) realizaram teste empírico para uma amostra de 105 países para os anos de 1960 e 1980. A hipótese central é a de que a forma funcional que liga urbanização e renda per capita pode ser representada por uma equação do tipo

$$
U^{-1}=a+b e^{g(y)}
$$

onde $U$ é a porcentagem da população urbanizada; $g$ é a função de $y$, a renda per capita; $e$ é a base de logaritmo natural; e $a$ e $b$ são os parâmetros a ser estimados. A principal característica dessa função é que a parcela urbana da população responde lentamente ao desenvolvimento econômico a baixos níveis de renda per capita, acelerando a níveis médios e tornando a responder lentamente a alto níveis de renda. Os resultados levam a que Mills e Becker defendam que a urbanização da população em um país ou região não ocorre de forma independente do desenvolvimento de sua economia.

Moomaw e Shatter (1996) estimaram os determinantes da porcentagem urbana da população, utilizando para tanto o modelo de Mills e Becker como referência. Como foi mencionado anteriormente, o ponto central do modelo é a relação entre o grau de desenvolvimento econômico e a urbanização. A idéia fundamental é que o desenvolvimento econômico aumenta o tamanho do mercado, o que, por sua vez, leva a uma maior divisão e especialização do trabalho. $\mathrm{O}$ desenvolvimento econômico engendraria um maior grau de urbanização por dois motivos: a maior divisão do trabalho, associada a um mercado maior, torna a economia com custos de transporte e comunicação mais importante (as vantagens das economias de escala); além disso, uma mudança na estrutura da economia, no sentido de torná-la realmente capitalista (distanciando-a, dessa forma, da economia agrícola tradicional), proporciona um grau maior de urbanização.

Nesse trabalho, utilizou-se o modelo proposto por Brueckner (1990) para testar os principais determinantes da migração no Nordeste.

\section{Modelo de estimação}

As considerações feitas anteriormente, bem como a disponibilidade de dados, fizeram com que se considerasse um conjunto de variáveis 
que, de acordo com a teoria, possam suportar importantes aspectos do processo de urbanização da população nordestina.

O modelo de estimação é definido por

$$
U r b=f\left(P I B_{P C}, Y r / Y u, A L F, D E N S,\right. \text { ENERG, D) }
$$

A descrição das variáveis é dada a seguir:

- Variáveis dependentes

As variáveis dependentes (representadas por $U r b$ ) são o total de pessoas que residem em áreas urbanas nas unidades espaciais escolhidas (as microrregiões nordestinas), e também a proporção da população urbana dessas unidades. As variáveis são $P O P U R B$ e $P R O P U R B$, respectivamente.

- Variáveis explicativas

$P I B_{P C}-\mathrm{O}$ objetivo da variável é captar a importância do desenvolvimento econômico como um dos principais determinantes da urbanização da população. O crescimento das atividades econômicas, como foi mencionado, aumenta o tamanho do mercado, o que eleva a importância das economias de aglomeração, tornando vantajosa a concentração das atividades na área urbana. Espera-se encontrar correlação positiva entre desenvolvimento econômico e a urbanização da população.

$Y r / Y u$ - É a razão entre o produto rural e o produto urbano. Seu objetivo é captar a importância do diferencial de renda entre as áreas rurais e urbanas como determinante da urbanização da população. Está ligada à supracitada discussão sobre a racionalidade do migrante no intuito de maximizar seus ganhos futuros nas áreas urbanas a partir da migração em direção às cidades. De acordo com a teoria, a variável $\mathrm{Yr} / \mathrm{Yu}$ apresentaria coeficiente negativo ao ser estimada como regressor de POPURB e PROPURB.

$D E N S$ - É a densidade da população rural (número de habitantes por quilômetro quadrado) das microrregiões. É uma forma de mensuração da ocupação da terra pelo homem, uma proxy para os fatores que expulsam a população das áreas rurais dada a forte pressão populacional sobre a terra. Espera-se encontrar correlação positiva entre a variável e a urbanização da população das microrregiões.

$A L F$-É o número de adultos alfabetizados por microrregião; uma proxy para o nível de educação da população naquela área, bem como da qualificação de sua mão-de-obra. De acordo com a teoria, um maior nível de educação torna a área em questão mais atraente à imigração da população à procura de melhores oportunidades e também de empresas em busca de trabalho qualificado e, conseqüentemente, maior produtividade do trabalhador. 
$E N E R G$-É o consumo de energia elétrica (MWh) por microrregião. É utilizada como proxy para a atividade industrial naquela unidade espacial. A relação entre industrialização e urbanização é muito forte. A indústria é uma atividade tipicamente urbana e, historicamente, o crescimento industrial foi o responsável pela força da cidade em relação ao campo. O aumento da atividade industrial produz, normalmente, um aumento da população urbana da área.

$D$ - O conjunto de variáveis dummy utilizado a fim de captar especificidades importantes de determinado grupo de microrregiões. São definidas as variáveis DRM (dummy para as microrregiões das regiões metropolitanas: Salvador, Recife e Fortaleza) utilizadas na análise empírica intraregional e a DCE (dummy para as microrregiões das capitais estaduais) estimadas quando a perspectiva de análise for intra-estadual. $\mathrm{O}$ objetivo das duas variáveis é captar o peso que essas RMs e capitais estaduais exercem sobre o sistema urbano regional e de cada estado. Serão também utilizadas as dummies D70 e D80, com o objetivo de capturar o efeito do tempo sobre o processo de urbanização.

\section{Base de dados e método de estimação}

Não há estimativas oficiais do PIB das microrregiões ou municípios no Brasil. O IBGE desagrega os valores do produto até o nível dos estados. Dessa forma, os PIB's das microrregiões nordestinas utilizados na análise empírica foram retirados do estudo "Dinâmica econômica das Regiões Metropolitanas Brasileiras", desenvolvido pelo IPEA, FADE e CME/PIMES e elaborado por Vergolino e Monteiro Neto (1996).

Os dados referentes à população urbana e rural das microrregiões foram agregados a partir das informações disponíveis nos municípios, encontradas nos Censos Demográficos em diversos anos. O mesmo ocorreu para o caso da variável que se refere ao número de pessoas alfabetizadas de cada microrregião. A área das microrregiões, utilizada na definição da variável referente à densidade rural das microrregiões, também foi obtida a partir de publicações do IBGE. ${ }^{6}$

As unidades espaciais escolhidas para teste empírico foram as microrregiões nordestinas nos anos de 1970, 1980, 1991, 1996. É a elas que as variáveis antes mencionadas se referem. A estimação do modelo descrito na seção anterior será realizada pelo método de mínimos quadrados e também dados de painel, utilizando-se para tanto a função log linear, cuja variável dependente é $L n P O P U R B$ e as independentes são $L n P I B p c, L n Y r / Y u, L n A L F$,

${ }^{6}$ IBGE, Cadastro de Cidades e Vilas do Brasil 1996. 
LnDENS, LnENERG, além das variáveis dummy $D R M, D 70$ e $D 80$, definidas na seção anterior.

A opção pela estimação por dados de painel decorre do fato de a estrutura dos dados se adequar ao método: "quando as observações estão disponíveis para várias unidades (famílias, firmas, cidades, etc.), em um determinado período de tempo (normalmente anos), algum método que combine os dados pode ser utilizado" (PINDYCK e RUBINFELD, 1991, p. 223).

O escopo de se combinarem dados de série temporal com os de corte transversal é justificado pelo fato de que se pode obter uma estimativa dos parâmetros mais eficiente do que no método de mínimos quadrados ordinários. "A motivação básica para se combinar dados de série temporal com corte transversal é que se o modelo é corretamente especificado, a combinação permite estimação, inferência e possivelmente previsão mais eficientes"(GUJARATI, 1995, p. 523).

\section{ANÁliSe dOS RESULTADOS}

A análise dos resultados será elaborada considerando-se duas perspectivas espaciais: regional, em que todas as microrregiões nordestinas são consideradas conjuntamente; e intra-estadual, em que as microrregiões são agrupadas segundo o limite de cada estado nordestino.

Na próxima seção serão apresentados os resultados da análise empírica para a perspectiva regional, obtidos a partir da estimação da função log linear pelo método de mínimos quadrados e de dados de painel, de acordo com o definido na seção anterior. A análise econométrica será exposta a partir da utilização da população urbana como variável dependente. Na seção seguinte, são revelados os resultados da análise a partir da perspectiva intra-estadual.

\section{Análise econométrica: o caso do Nordeste}

A análise empírica se inicia com a exposição dos resultados econométricos da estimação do modelo adotado para toda a Região Nordeste, de maneira que encontram-se presentes 186 microrregiões nordestinas para o intervalo $1970 / 1996 .^{7}$ Inicialmente, foram estimadas por mínimos qua-

${ }^{7}$ Não estão presentes as microrregiões de Chorozinho, no Ceará, e Fernando de Noronha, em Pernambuco, por questões de disponibilidade de dados. 
drados ordinários as equações para os anos de 1970, 1980, 1990 e 1996, utilizando-se a variável dependente log da população urbana, LnPOPURB, assim como as variáveis independentes descritas no capítulo anterior. Entretanto, o teste para normalidade dos resíduos - Jarque-Bera - revelou a não aceitação da hipótese nula de distribuição Normal dos resíduos. A análise do termo de resíduo também apontou a presença significativa de outliers na amostra utilizada.

A não verificação do pressuposto clássico da normalidade dos resíduos, bem como a presença de outliers, tornou relevante a estimação a partir de um método robusto. Por robusto, nesse caso, entende-se o modelo de regressão linear adequado à não normalidade dos resíduos e à presença dos outliers. Estimou-se, portanto, o modelo de regressão linear robusto, que utiliza a mediana, em vez da média, na estimação dos parâmetros estudados. Enquanto a média pode ser afetada significativamente por outliers, a mediana possui a propriedade de ser mais resistente a esse tipo de problema.

A Tabela 3 mostra os resultados da estimação linear robusta e de dados de painel, utilizando-se como variável dependente o log da população urbana das microrregiões. A população urbana é estimada como função log linear de $L n P I B p c, L n Y r / Y u, L n A L F, L n D E N S, L n E N E R G$, além das variáveis dummy $D R M, D 70$ e $D 80$, definidas anteriormente.

$\mathrm{O}$ conjunto de equações de $\mathrm{n}^{\circ} 1$ a 5 mostra os resultados para o total da amostra, referentes aos anos explicitados na última linha da tabela, sem incluir as variáveis dummy. Analisando-se as cinco equações na perspectiva das variáveis, constata-se que a variável LnPIBpc apresentou-se altamente significante para os três anos seguidos e com o sinal coerente, como predito pela teoria. No ano de 1996, esta variável deixa de apresentar qualquer importância estatística, embora continue indicando uma relação funcional coerente com a variável dependente. São resultados que oferecem suporte estatístico à teoria, que afirma que o desenvolvimento econômico, medido pelo PIB per capita, apresenta uma forte associação com o processo de urbanização da população. A variável Ln $Y_{r} / Y_{u}$ apresenta forte aderência estatística aos dados para os anos de 1970, 1980 e 1996, e com um sinal coerente para os três primeiros anos e com sinal positivo para 1996. A variável $L n A L F$, que mede o papel da educação no processo de urbanização, mostrou-se altamente significante do ponto de vista estatístico e com sinal positivo, coerente portanto com o predito pela teoria. Esses resultados podem sugerir que o maior nível de educação, tendo em vista que aumenta a expectativa de rendimentos futuros do indivíduo, torna as áreas urbanas mais atraentes à migração de origem rural e de cidades de menor porte para áreas urbanas maiores. Vários autores encontraram resultados semelhantes 
aos aqui apresentados (LIMA, 1996; ANDRADE e SERRA, 1998; CARLINO e MILLS, 1985; MOOMAW e SHATTER, 1996; CARLINO e MILLS, 1985; MILLS eLUBUELLE, 1995).

Tabela 3 - NORDESTE DO BRASIL - DETERMINANTES DA POPULAÇÃO URBANA

\begin{tabular}{|c|c|c|c|c|c|c|c|c|c|c|}
\hline Variável & Eq.(1) & Eq. (2) & Eq. (3) & Eq. (4) & Eq. (5) & Eq. (6) & Eq. (7) & Eq. (8) & Eq. (9) & Eq. (10) \\
\hline LnPIBpc & $\begin{array}{c}0,21 * * * \\
(2,38)\end{array}$ & $\begin{array}{l}0,16^{* *} \\
(3,02)\end{array}$ & $\begin{array}{l}0,12 * * \\
(2,58)\end{array}$ & $\begin{array}{c}0,03 \\
(-0,39)\end{array}$ & $\begin{array}{c}0,16^{* * *} \\
(5,76)\end{array}$ & $\begin{array}{l}0,2 * * * \\
(4,56)\end{array}$ & $\begin{array}{l}0,16^{* *} \\
(2,95)\end{array}$ & $\begin{array}{l}0,11 * * \\
(2,44)\end{array}$ & $\begin{array}{c}0,04 \\
(0,44)\end{array}$ & $\begin{array}{c}1,61 * * * \\
(5,25)\end{array}$ \\
\hline $\mathrm{LnYr} / \mathrm{Yu}$ & $\begin{array}{c}-0,09 * * * \\
(-3,52)\end{array}$ & $\begin{array}{c}-0,09 * * * \\
(-3,13)\end{array}$ & $\begin{array}{c}-0,003 \\
(-0,2)\end{array}$ & $\begin{array}{c}0,001 * * * \\
(3,88)\end{array}$ & $\begin{array}{l}-0,004 \\
(-0,23)\end{array}$ & $\begin{array}{c}-0,11 * * * \\
(-3,61)\end{array}$ & $\begin{array}{c}-0,13 * * * \\
(-3,66)\end{array}$ & $\begin{array}{l}-0,007 \\
(-0,34)\end{array}$ & $\begin{array}{c}0,002 * * * \\
(8,77)\end{array}$ & $\begin{array}{c}-0,02 \\
(-1,09)\end{array}$ \\
\hline LnALF & $\begin{array}{c}0,94 * * * \\
(30,22)\end{array}$ & $\begin{array}{c}0,93 * * * \\
(31,33)\end{array}$ & $\begin{array}{c}0,94 * * * \\
(18,08)\end{array}$ & $\begin{array}{l}- \\
-\end{array}$ & $\begin{array}{c}0,98 * * * \\
(51,1)\end{array}$ & $\begin{array}{c}0,95 * * * \\
(30,24)\end{array}$ & $\begin{array}{c}0,96 * * * \\
(29,65)\end{array}$ & $\begin{array}{c}0,94 * * * \\
(17,39)\end{array}$ & - & $\begin{array}{c}0,98 * * * \\
(47,18)\end{array}$ \\
\hline LnDENS & $\begin{array}{c}0,07 * * * \\
(3,24)\end{array}$ & $\begin{array}{c}0,15^{* * *} \\
(5,89)\end{array}$ & $\begin{array}{c}0,04 * \\
(1,94)\end{array}$ & $\begin{array}{c}0,07 \\
(1,42)\end{array}$ & $\begin{array}{l}-0,014 \\
(-0,91)\end{array}$ & $\begin{array}{c}0,08 * * * \\
(3,35)\end{array}$ & $\begin{array}{c}0,14 * * * \\
(5,39)\end{array}$ & $\begin{array}{c}0,04 * * \\
(1,96)\end{array}$ & $\begin{array}{c}0,07 \\
(1,18)\end{array}$ & $\begin{array}{l}-0,008 \\
(-0,52)\end{array}$ \\
\hline LnENERG & - & $\begin{array}{l}- \\
-\end{array}$ & $\begin{array}{l}0,019 \\
(0,41)\end{array}$ & $\begin{array}{c}0,74 * * * \\
(17,34)\end{array}$ & - & $\begin{array}{l}- \\
-\end{array}$ & $\begin{array}{l}- \\
-\end{array}$ & $\begin{array}{c}0,02 \\
(0,47)\end{array}$ & $\begin{array}{c}0,74 * * * \\
(14,44)\end{array}$ & - \\
\hline DRM & $\begin{array}{l}- \\
-\end{array}$ & $\begin{array}{l}- \\
-\end{array}$ & - & - & - & $\begin{array}{c}-0,29 \\
(-1,44)\end{array}$ & $\begin{array}{c}-0,38 \\
(-0,43)\end{array}$ & $\begin{array}{l}-0,05 \\
(-0,3)\end{array}$ & $\begin{array}{c}0,28 \\
(0,64)\end{array}$ & $\begin{array}{c}* * *_{-} 0,35 \\
(-2,52)\end{array}$ \\
\hline D70 & $\begin{array}{l}- \\
-\end{array}$ & $\begin{array}{l}- \\
-\end{array}$ & $\begin{array}{l}- \\
-\end{array}$ & $\begin{array}{l}- \\
-\end{array}$ & - & - & - & - & - & $\begin{array}{c}-0,034 \\
(-0,8)\end{array}$ \\
\hline D80 & - & $\begin{array}{l}- \\
-\end{array}$ & $\begin{array}{l}- \\
-\end{array}$ & - & $\begin{array}{l}- \\
-\end{array}$ & $\begin{array}{l}- \\
-\end{array}$ & $\begin{array}{l}- \\
-\end{array}$ & $\begin{array}{l}- \\
-\end{array}$ & $\begin{array}{l}- \\
-\end{array}$ & $\begin{array}{l}-0,036 \\
(-0,94)\end{array}$ \\
\hline Constante & $\begin{array}{c}-0,89 * * \\
(-2,38)\end{array}$ & $\begin{array}{l}-0,78^{*} \\
(-1,77)\end{array}$ & $\begin{array}{c}-0,39 \\
(-1,09)\end{array}$ & $\begin{array}{c}3,45 * * * \\
(6,97)\end{array}$ & $\begin{array}{c}-0,74 * * * \\
(-3,28)\end{array}$ & $\begin{array}{c}-1,07 * * * \\
(-2,38)\end{array}$ & $\begin{array}{c}-1,17^{* *} \\
(-2,52)\end{array}$ & $\begin{array}{c}-0,39 \\
(-0,38)\end{array}$ & $\begin{array}{c}3,61^{* * *} \\
(5,98)\end{array}$ & $\begin{array}{c}-0,77 * * * \\
(-2,88)\end{array}$ \\
\hline $\mathrm{F}$ & - & - & - & - & 424 & - & - & - & - & 640 \\
\hline $\mathrm{R}^{2}$ & 0,69 & 0,59 & 0,67 & 0,76 & 0,88 & 0,69 & 0,61 & 0,67 & 0,77 & 0,89 \\
\hline Obs. & 186 & 186 & 186 & 186 & 558 & 186 & 186 & 186 & 186 & 558 \\
\hline Ano & 1970 & 1980 & 1990 & 1996 & $1970 / 90$ & 1970 & 1980 & 1990 & 1996 & $1970 / 90$ \\
\hline
\end{tabular}

NOTA: Variável dependente: log da população urbana (LnPOPURB) O número em parênteses é a estatística t.

*Significante a $10 \%, * *$ siginificante a $5 \%$, *** significante a $1 \%$

A variável $L n D E N S$ mostrou-se importante para os três primeiros anos e não-significante estatisticamente para o ano de 1996, embora apresentando sinais coerentes. O mesmo se pode dizer a respeito da variável $L n E N E R G$. Nesse conjunto de cinco equações, o fato inusitado está relacionado à equação No. 5 que apresenta o melhor grau de ajustamento, melhor $\mathrm{R}^{2}$, mas com a variável $L n P I B p c$ deixando de ser estatisticamente significante quando se elimina a variável Educação. Nesse caso a variável $L n E N E R G$ passa a apresentar significância estatística. Torna-se necessário avançar nos testes para verificar a razão desse fenômeno. As equações de números 6 a 9 são parcialmente idênticas às já analisadas e a única diferença está na inclusão das variáveis dummy. A inclusão dessas variáveis não aumentou em nada o nível de significância estatística dos parâmetros das equações anteriores nem contribuiu para uma melhoria significativa no grau de ajustamento das equações. 
As equações (5) e (10) remetem à regressão com os dados agrupados em painel para o intervalo 1970/90. A equação (5) confirma o bom desempenho relativo às variáveis $L n P I B_{P C}$ e $L n A L F$, cujos coeficientes possuem os sinais esperados e são significantes. O coeficiente de $\mathrm{LnYr} / \mathrm{Yu}$ traz o sinal de acordo com a teoria, entretanto não significante. A variável LnDENS, no entanto, passa a exibir sinal negativo - incompatível com a teoria. A densidade populacional dos habitantes das áreas rurais das microrregiões é utilizada como proxy dos fatores que expulsam a população do campo, mais notadamente a pressão da população sobre a terra nas áreas rurais. $\mathrm{O}$ valor negativo do coeficiente de $L n D E N S$ sugere que os fatores de expulsão exercem um efeito negativo sobre a população urbana da microrregião. Deve-se mencionar, contudo, que o coeficiente não se apresenta estatisticamente significante, além de ter valor muito baixo. $\mathrm{O}$ grau de ajuste da equação (5) pode ser considerado bom com o $\mathrm{R}^{2}$ de 0,88 e a estatística $\mathrm{F}$ significante. Em relação à equação (10), que pode ser comparada com a (5), constata-se que a introdução da variável dummy não contribuiu para melhorar a aderência do modelo. Na equação (10), o coeficiente de $D R M$ possui sinal negativo; entretanto, apresenta-se estatisticamente significante. Os coeficientes das dummies $D 70$ e D80 não foram significantes. A estimação das equações com variáveis dummy elencadas evidenciou, de forma geral, resultados pobres. Com relação ao grau de ajustamento, a introdução dessas variáveis proporcionou uma elevação muito pequena nos $\mathrm{R}^{2}$.

\section{Análise econométrica: o caso dos Estados Nordestinos}

A análise empírica pela perspectiva estadual é realizada a partir da estimação por dados de painel da função log linear que tem como variável dependente $\operatorname{LnPOPURB}$ (log da população urbana da microrregião) para o período 1970/1990. Os regressores considerados são $L n P I B p c, L n Y r / Y u$, $L n A L F, L n D E N S, D C E, D 70$ e $D 80$. Nesta etapa foram consideradas para análise somente as especificações que incluíssem as variáveis dummies por apresentar melhores resultados econométricos.

Na Tabela 4 encontram-se elencados os resultados da estimação por dados de painel da função log linear, que tem como variável dependente a população urbana de cada microrregião com a inclusão das variáveis dummies. As especificações sem dummies foram mais pobres e dessa forma descartadas. Os resultados para $D C E$ são, também nesse caso, pobres; entretanto, os resultados para $D 70$ e $D 80$, utilizadas para captar o efeito do tempo, são significantes para todos os estados. $\mathrm{O}$ bom desempenho dessas variáveis se reflete em uma melhora sensível no grau de ajustamento das equações. 
De maneira geral, a análise empírica a partir da perspectiva estadual veicula resultados importantes acerca dos determinantes da urbanização considerados. Entretanto, o aspecto relevante dessa análise se encontra nos resultados apontados pelas variáveis $L n Y r / Y u$ e $L n A L F$.

Diferentemente da perspectiva regional, a variável $L n Y r / Y u$ apresenta resultados relevantes para explicar o diferencial de renda entre as áreas urbanas e rurais. A mesma situação pode ser observada quando se analisam os resultados de $L n A L F$. Uma das explicações para o melhor desempenho dessas variáveis pode ser o fato de a análise estadual permitir o afloramento de aspectos particulares do crescimento econômico estadual, que refletem as diferentes realidades de cada espaço. De acordo com Burian (1997),

Análises de espaços geográficos mais limitados permitem uma melhor identificação dos determinantes do processo de desenvolvimento econômico, que se processa nessa localidade, já que os efeitos espaciais de qualquer fenômeno econômico tendem a desaparecer com o aumento da distância, podendo até ser anulado quando esta for bastante grande (BURIAN, 1997, p. 44).

Tabela 4 - NORDESTE - DETERMINANTES DA POPULAÇÃO URBANA SEGUNDO OS ESTADOS

\begin{tabular}{lcccccccccccc}
\hline Variável & MA & PI & $\mathbf{C E}$ & $\mathbf{R N}$ & $\mathbf{P B}$ & $\mathbf{P E}$ & $\mathbf{A L}$ & $\mathbf{S E}$ & $\mathbf{B A}$ \\
\hline LnPIBpc & 0,01 & $-0,009$ & $0,18^{* * *}$ & $0,32^{* *}$ & $0,41^{* * *}$ & $0,16^{* * *}$ & $0,32 * * *$ & 0,11 & $0,26^{* *}$ \\
& $(0,02)$ & $(-0,07)$ & $(3,11)$ & $(-1,98)$ & $(3,9)$ & $(2,85)$ & $(3,43)$ & $(1,53)$ & $(2,01)$ \\
LnYr/Yu & 0,11 & $* * *-0,27$ & $-0,06$ & 0,01 & $-0,05$ & $-0,05$ & $-0,06$ & $-0,14^{* * *}$ & 0,027 \\
& $(1,38)$ & $(-3,72)$ & $(-1,5)$ & $(0,23)$ & $(-1,1)$ & $(-1,2)$ & $(-0,94)$ & $(-3,16)$ & $(0,31)$ \\
LnALF & $0,97 * * *$ & $0,65^{* * *}$ & $1,06^{* * *}$ & $0,97 * * *$ & $0,96^{* * *}$ & $1,01 * * *$ & $0,83 * * *$ & $0,8^{* * *}$ & $1,02^{* * *}$ \\
& $(10,73)$ & $(6,8)$ & $(37,26)$ & $(12,93)$ & $(12,03)$ & $(23,39)$ & $(7,61)$ & $(8,85)$ & $(13,09)$ \\
LnDENS & 0,05 & $0,28^{* * *}$ & 0,02 & $-0,08$ & 0,06 & $0,08 * * *$ & 0,21 & 0,03 & $-0,27 * * *$ \\
& $(0,75)$ & $(4,12)$ & $(0,6)$ & $(-0,97)$ & $(1,57)$ & $(2,74)$ & $(1,18)$ & $(0,56)$ & $(-4,93)$ \\
DCE & $-0,14$ & 0,14 & $0,39 * *$ & $-0,048$ & $-0,27$ & $-0,358$ & 0,05 & 0,02 & $-0,77$ \\
& $(-0,33)$ & $(0,7)$ & $(-2,49)$ & $(-0,19)$ & $(-1,14)$ & $(-1,72)$ & $(0,23)$ & $(0,09)$ & $(-1,88)$ \\
D70 & $-0,61 * * *$ & $-0,27 * * *$ & 0,02 & 0,14 & 0,1 & 0,06 & 0,03 & $-0,17$ & 0,18 \\
& $(-4,1)$ & $(-2,47)$ & $(0,45)$ & $(1,36)$ & $(1,08)$ & $(1,02)$ & $(0,25)$ & $(-1,36)$ & $(1,38)$ \\
D80 & $-0,48 * * *$ & $-0,21 * *$ & $-0,12 * * *$ & $-0,09$ & $-0,53$ & 0,02 & $-0,08$ & $-0,14$ & $0,43 * * *$ \\
& $(-3,71)$ & $(-2,28)$ & $(-2,74)$ & $(-1,01)$ & $(-1,64)$ & $(0,5)$ & $(-0,7)$ & $(-1,51)$ & $(3,9)$ \\
Constante & 0,47 & $3,28 * * *$ & $-1,79 * * *$ & $-1,5 * *$ & $-2,43 * * *$ & $-1,28 * *$ & $-1,06$ & 1,24 & $-1,52$ \\
& $(1,35)$ & $(2,53)$ & $(-4,32)$ & $(-1,97)$ & $(-2,79)$ & $(-2,2)$ & $(-1,48)$ & $(1,1)$ & $(-1,56)$ \\
& & & & & & & & & \\
F & 47,31 & 135 & 501 & 115 & 95 & 288 & 99 & 137 & 62 \\
R 2 & 0,85 & 0,96 & 0,97 & 0,94 & 0,91 & 0,97 & 0,95 & 0,96 & 0,83 \\
Obs. & 63 & 45 & 96 & 57 & 69 & 54 & 39 & 39 & 96 \\
Ano & $1970 / 90$ & $1970 / 90$ & $1970 / 90$ & $1970 / 90$ & $1970 / 90$ & $1970 / 90$ & $1970 / 90$ & $1970 / 90$ & $1970 / 90$ \\
\hline
\end{tabular}

NOTA: Variável dependente: $\log$ da população urbana (LnPOPURB)

$\mathrm{O}$ número em parênteses é a estatística t.

*Significante a $10 \%, * *$ siginificante a $5 \%, * * *$ significante a $1 \%$ 
A análise intra-estadual poderia captar especificidades de cada estado que permitiriam uma estimação mais eficiente dos parâmetros. Tem-se então que, de maneira geral, os resultados da análise empírica nas perspectivas espaciais adotadas sugerem importantes aspectos dos determinantes do processo de urbanização na Região; encontram-se de acordo com o preconizado pela teoria e segundo os diversos estudos de caráter empírica destacados no decorrer do presente trabalho.

\section{CONCLUSÕES}

O objetivo central do presente trabalho está voltado para a análise empírica dos principais determinantes do processo de urbanização para o caso da Região Nordeste.

As evidências econométricas apresentadas nas seções anteriores estão, em larga medida, compatíveis com o preconizado pela teoria e com os resultados observados na maior parte dos trabalhos empíricos. A análise dos resultados a partir das perspectivas indica que o desenvolvimento econômico (medido sob a forma de PIBpc) constitui um forte determinante da população urbana regional, bem como da proporção dessa população sobre a população total. Esse resultado reflete um período no qual a economia nordestina apresenta desempenho notável, especialmente a década de 1970 e parte de 1980. Ao longo da década de 1970, a economia regional foi marcada pela implantação de grandes projetos públicos e privados, localizados, principalmente, em torno das capitais estaduais. Destacam-se o Pólo Petroquímico de Camaçari, na Bahia, o Pólo Têxtil e de Confecção, em Fortaleza, e o Complexo Metal-Mecânico de Recife. Na década de 1980, algumas microrregiões do interior nordestino passam a apresentar relativo dinamismo nas suas estruturas produtivas, como foi o caso do complexo agro-industrial de Petrolina/Juazeiro (MAIA GOMES e VERGOLINO, 1995).

Conclusivamente, tem-se que os resultados da análise empírica encontram-se de acordo com o preconizado pela abordagem neoclássica. $\mathrm{O}$ processo de desenvolvimento econômico observado na Região no decorrer das décadas de 1970 e 1980 teve grande importância na urbanização da população nordestina. $\mathrm{O}$ aumento no nível educacional da população, que se revela como um dos fatores de modernização da economia, também desempenha um papel relevante. O desenvolvimento da economia favoreceu as cidades, gerando um diferencial de renda em seu favor que constitui um elemento de grande importância para a atração de pessoas do campo, uma 
das principais características de um processo que deslocou, no Nordeste, grande parte da população em direção às cidades.

\title{
RESUMO
}

O estudo dos principais determinantes do processo de urbanização da Região está diretamente ligado à combinação dos fatores de expulsão da população dos quadros rurais com os fatores de atração dos contingentes em direção às cidades. Esse é o ponto central da estrutura do presente trabalho, cujo objetivo central é investigar o processo de urbanização da Região Nordeste do Brasil no período 19701996. Procura-se mostrar, por meio da análise de literatura de história econômica, a importância da formação econômica da Região na definição de seu sistema urbano. Em seguida, destaca-se alguns aspectos da migração rural-urbana e sua importância no crescimento da população urbana nordestina. Em seção especial aborda-se a dinâmica recente do processo de urbanização regional e sua relação com a concentração das atividades econômicas verificada no período estudado. A partir de um modelo econométrico específico, estimam-se os principais determinantes do processo de urbanização da Região no período 1970-1996.

Palavras-chave: urbanização; crescimento urbano; migração; Nordeste.

\begin{abstract}
The study of the main factors leading to the urbanization of the Brazilian Northeast is linked to the combination of factors leading to the expulsion of rural populations with the factors that attraction them to the cities. This is the basis of this article, aiming at analyzing the urbanization process of the Brazilian Northeast from 1970 to 1996. Using economic history, it is shown the relevance of its economic development in setting up its urban systems. Next, the impact of the migration from rural areas to the cities on the urban population growth is highlighted. In what follows, we approach the dynamics of regional urbanization and its link with the concentration of economic activities that took place in that time period. Using an econometric model, we estimate the main determinants of the urbanization process taking place in the Brazilian Northeast over 1970 to 1996.

Key-words: urbanization; urban growth; migration; northeast.
\end{abstract}




\section{REFERÊNCIAS}

ANDRADE, Manuel Correia de. A terra e o homem no Nordeste. São Paulo: Brasiliense, 1963.

BARROS, Marcelo Andrade Bezerra. Educação, crescimento econômico e convergência dos PIB's per capita no Nordeste do Brasil: uma análise microrregional 1970/91. Recife, 1997. Dissertação (Mestrado) - PIMES, Universidade Federal de Pernambuco.

BRUECKNER, J. Analyzing third world urbanization: a model with empirical evidence. Economic Development and Cultural Change, v.38, p. 587-609, 1990.

. The structure of urban equilibria: a unified treatment of Muth-Mills Model. In: MILLS, Edwin S. Handbook of Regional and Urban Economics. [S.1.]: Elsevier Sciense Publishers B. V., 1987. v. 2, cap. 20, p. 821-845.

BURIAN, Cláudio. O processo de convergência do produto per capita municipal em Minas Gerais, 1985-1995. Revista Econômica do Nordeste, v. 28, n. especial, jul. 1997.

CANO, Wilson. Desequilibrios regionais e concentração industrial no Brasil: 19301970. Campinas, 1985. Tese (Doutorado) - Unicamp.

CARLINO, Gerald; MILLS, Edwin S. The determinants of county growth. Federal Reserve Bank of Philadelphia, n. 85-3, 1985.

DUARTE, Renato S. Migration and urban poverty in northeast Brazil. Glasgow, 1979. Tese (Doutorado) - University of Glasgow.

FURTADO, Celso. Formação econômica do Brasil. 27. ed. São Paulo: Companhia Editora Nacional, 1998.

GUJARATI, Damodar N. Basic Econometrics. 3. ed. New York: Mc Graw-Hill International Editions, 1995.

HARRIS, J. L.; TODARO, M. P. Migration, unemployment, and development: a two sector analysis. American Economic Review, n. 60, p. 126-142, 1970.

HOBSBAWM, Eric. Era dos extremos: o breve século XX. 2. ed. São Paulo: Companhia das Letras, 1995.

HOLANDA, Sérgio Buarque de. Raizes do Brasil. 17. ed. Rio de Janeiro: Brasiliense, 1984.

IBGE. Censo demográfico. 1940, 1950, 1960, 1970, 1980, 1991.

IBGE. Contagem da população - 1996.

LIMA, Ricardo Chaves. Migrações rurais em áreas de irrigação pública no Nordeste. Revista Econômica do Nordeste, Fortaleza, v. 27, n. 4, p. 569-582, out./dez. 1996.

LINS, José Caldas. Desenvolvimento urbano do Nordeste: subsídios para uma política regional. Estudos nordestinos sobre crescimento urbano. Recife, p. 141-166.

LUBAMBO, Cátia W.; SANTOS, Taís de Freitas, TEIXEIRA; Pery. Campo vila ou cidade: onde vive a gente do Nordeste? A trajetória da urbanização de 60 a 91. In: ENCONTRO NACIONAL DA ANPUR, 5., 1995, Belo Horizonte. Anais... Belo Horizonte: [s.n.],1995. v. 2. p. 703-714. 
MAIA GOMES, Gustavo; VERGOLINO, José Raimundo. A macroeconomia do desenvolvimento nordestino: 1960/94. Brasília: IPEA, 1995. Texto para Discussão n. 372.

MARTINE, George. A redistribuição espacial da população brasileira durante a década de 80. Brasília: IPEA, 1994. Texto para Discussão n. 329.

MILLS, Edwin S. Urban Economics. 2. ed. Princeton: Scott, Foresman and Company, 1980.

MILLS, Edwin S.; LUBUELE, Luan S. Projecting growth of metropolitan areas. Journal of Urban Economics, v. 37, p. 344-360, 1995.

Press, 1986.

.; BECKER, C. Studies in Indian urban development. Oxford: Oxford Univ.

.; HAMILTON, B. W. Urban Economics. 4. ed. Princeton: Scott, Foresman and Company, 1989.

MOOMAW, Ronald; SHATTER, Ali M. Urbanization and economic development: a bias toward large cities? Journal of Urban Economics, v. 40, p. 13-37, 1996.

MOURA, Hélio A. Migrações para as grandes cidades do Nordeste: intensidade e características demográficas. Revista Econômica do Nordeste, Fortaleza, 1975.

. A recente dinâmica demográfica do Nordeste: seus determinantes e implicações.

Revista Econômica do Nordeste, Fortaleza, v. 16, n. 2, p. 155-181, abr./jun. 1985.

PINDYCK, Robert S.; RUBINFELD, Daniel L. Econometric models and economic forecasts. 3. ed. New York: Mc Graw-Hill, 1991.

PRADO JÚNIOR, Caio. História econômica do Brasil. 21. ed. São Paulo: Brasiliense, 1978.

SANTOS, Valdeci Monteiro dos. Regiões metropolitanas de Salvador, Recife e Fortaleza: diferentes processos de industrialização. In: ENCONTRO NACIONAL DA ANPUR, 7.,1997, Recife. Anais... Recife: UFPE, 1997. v. 2. p. 853-877.

SINGER, Paul. Desenvolvimento econômico e evolução urbana. 2. ed. São Paulo: Companhia Editora Nacional, 1977.

TOllENARE, L. F. de. Notas Dominicais. [1817] Secretaria da Educação e Cultura. Edição do Governo de Pernambuco, 1977.

Recebido em 10 jun. 2005

Aprovação final em 17 jul. 2005 